\title{
Kompleks Yapı ve Alanlarda Yersel Lazer Tarama Teknolojisinin Kullanımı
}

\author{
Mücahit Emre ORUÇ*1® , Gizem BAȘ²@ \\ ${ }_{1}^{1}$ Mersin Üniversitesi, Fen Bilimleri Enstitüsü, Uzaktan Algılama ve Coğrafi Bilgi Sistemleri Anabilim Dalı, Mersin, Türkiye \\ ${ }^{2}$ Aksaray Üniversitesi, Mühendislik Fakültesi, Harita Mühendisliği, Aksaray, Türkiye
}

\author{
Anahtar Kelimeler \\ Yersel lazer tarama, \\ Fotogrametri, \\ 3B model, \\ Nokta bulutu.
}

\begin{abstract}
ÖZ
Bilim ve teknolojik gelişmelerin sonucunda birçok yeni teknoloji, yazılım ve donanımlar ortaya çıkmaktadır. Bu teknolojik gelișmeler her bir alanda kendini göstermekte ve ilgili alanlarda kolaylıklar sağlamaktadır. Yersel lazer tarama tekniği de bu teknolojilerden biridir. Birçok disiplin tarafından kullanılan, sayısız iş ve projelerde kullanılarak alanına kolaylıklar sağlayan bir teknoloji olmuştur. Ülkemizde bu teknoloji maliyetli olarak görülüp çok fazla çalışma alanı bulamamış olması aslında yapılacak olan işin daha uzun süre ve maliyetli olarak yapılmasına sebep olmaktadır. Gelişmekte olan bir teknik olduğu için ilerleyen zamanlarda daha geniş bir çalıșma kitlesine ulaşacağı öngörülebilir. Yersel lazer tarama teknolojisi kullanıldığı birçok disipline kısa zamanda geniş ve girilmesi zor alanları tarayarak verileri yüksek çözünürlük ve kalitede ortaya koyabilmektedir. Kullanım alanlarının çeşitli olması en büyük avantajlarından biridir. Gerçekleştirilen çalışmanın amacı yersel lazer tarama işlemi yapılırken dikkat edilmesi gereken hususlar ve tarama işlemi sırasında tekniğin eksi ve artı yönlerini ve bu noktada ortaya çıkan eksiklerin çalışma alanına etkisi, elde edilen verinin bu eksikliklerden etkilenmesi ve farklı ölçüm metotları ile çevresel faktörlerin bu tekniği etkilediği yönleri öğrenilmeye çalışılmıștır.
\end{abstract}

\section{Use of Terrestrial Laser Scanning Technology in Complex Structures and Areas}

\section{Keywords}

Terrestrial laser scanning, Photogrammetry,

3D model,

Point cloud.

\begin{abstract}
As a result of scientific and technological developments, many new technologies, software and hardware are emerging. These technological developments show themselves in every field and provide convenience in related fields. Terrestrial laser scanning technique is one of these technologies. It has become a technology that is used by many disciplines and provides convenience to its field by being used in countless works and projects. The fact that this technology is seen as costly in our country and cannot find many working areas actually causes the work to be done for a longer time and more costly. Since it is a developing technique, it can be predicted that it will reach a wider study audience in the future. Terrestrial laser scanning technology can reveal data in high resolution and quality by scanning large and difficult areas in a short time in many disciplines where it is used. The variety of usage areas is one of its biggest advantages. The aim of the study was to learn the points to be considered while performing the terrestrial laser scanning process, the minus and plus aspects of the technique during the scanning process and the effect of the deficiencies that occur at this point on the study area, the effects of the obtained data from these deficiencies, and the aspects that different measurement methods and environmental factors affect this technique. .
\end{abstract}




\section{GİRiş}

Günümüzde teknolojinin gelișmesi ile birlikte fazla işgücü gerektiren, zaman alan ve maliyeti yüksek yöntemler yerini yeni teknolojik yöntemlere bırakmaya başlamıştır (Erener \& Yakar, 2012; Alptekin vd., 2019). $\mathrm{Bu}$ noktada da birçok disiplinde yersel lazer tarama tekniği kendini göstermeye başlamıștır. Lazer tarama yöntemi günümüz çalışmalarında, proje ve ölçüm ișlemlerinde sıklıkla kullanılmaktadır. Gerek haritacılık alanında gerekse diğer disiplinler tarafindan kullanılması bu tekniğin, hedeflenen amaçlarda işe yarar bir katkı sağladığı görülmektedir (Yakar vd., 2009; Yılmaz vd., 2018). Yersel lazer tarama teknolojisi ile ilgili yapılan araştırmalar ve uygulama alanları incelendiğinde farklı farklı alanlarda kullanıldığı görülmektedir. Yakın zaman çizgisinde genel olarak lazer tarama teknolojisinin kullanım alanlarına bir bakış yapıldığında, bu teknoloji en çok harita mühendisliği olmakla birlikte mimari çalışmalar, arkeolojik eserlerin incelenmesi, tarihi eserlerin belgelenmesi, deformasyon ölçmeleri, kentlerin modellenmesi, olay yeri inceleme ve kriminoloji çalışmaları gibi alanlarda kullanılan büyük öneme sahip teknolojidir. (Sabuncu \& Özener 2020).

Yersel lazer tarama teknolojisi 3B modellemeye ilişkin birçok alanda ya da multidisipliner alanlarda kullanılmakta ve kullanılmaya gelişerek devam etmektedir. $\mathrm{Bu}$ teknoloji çoğunlukla aşağıda verilen alanlarda kullanılmaktadır (Ulvi \& Yakar 2014).

$>$ Maden alanlarının modellenmesinde,

$>$ Endüstriyel yapıların belgelenmesinde,

$>$ Arkeoloji çalışmalarında,

$>$ Mimarlık sektöründe,

$>$ Otomotiv sektörü ve robotik çalışmalarda,

$>$ CBS çalışmalarında,

$>$ Kıyıların incelenmesi çalışmalarında,

$>$ Volkanik faaliyetlerin analizinde,

$>$ Deformasyon incelemede,

$>$ Çevresel çalışmalarda,

$>$ Tarihi ve kültürel eserlerin belgelenip modellenmesinde,

$>$ Ormancllk ve orman amenajman planlama çalışmalarında (Oruç \& Öztürk 2021),

$\mathrm{Bu}$ uygulamada lazer tarama teknolojisinin etkisini en iyi şekilde görmek için uygulamada hem çeşitli objelerin olması hem de genel olarak bölgenin yüzey alanında ve geometrik yapısında benzerliklerin olduğu bölge tercih edilmiștir. Bu doğrultuda lazer tarama teknolojisinin taramalar sonunda verileri işlemede nasıl kabiliyet gösterdiği görülmek istenmiştir. Bu çalışmada kompleks bir yapı tercih edildiği için yapının üst kısımlarına lazer ışınları ulaşamadığı için bu noktalarda veri elde edilememiștir. Ama bu gibi durumlarda İHA sistemleri ile yukardan çekilen fotoğrafların modellenmesi ve lazer verileri ile entegre edilmesi sonucu bu açıklık kapatılabilmektedir (Hamal vd. 2020).

Gerçekleştirilen çalışmanın amacı yersel lazer tarama işlemi yapılırken dikkat edilmesi gereken hususları, işlem esnasında tekniğin eksi ve artı yönlerini ve bu noktada ortaya çıkan eksiklerin çalışma alanına etkisini, elde edilen verinin bu eksikliklerden etkilenmesini ve farklı ölçüm metotları ile çevresel faktörlerin bu tekniği etkilediği yönleri öğrenmeye çalışmaktır.

3B veri ișleme ve veriyi görselleștirmedeki gelişmeler, yapılan taramalar sonucunda üretilen büyük miktarlardaki nokta bulutlarını ve bunun içinde nokta verisini kullanılabilir hale getirmiştir. Uygulamada birçok alanda karşılaşılan ya da karşılaşılabilecek sorunları çözmek ve bunların gerçek modellerini elde etmek için ölçümler yapmak ve bu ölçümleri tamamlamak gerekir (Yılmaz \& Yakar, 2008). Bu ölçümler sonucu yapılan modelleri inceleyerek, ölçülen nesneler hakkında yeni bilgileri öğrenilebilinecektir. 3B Modelleme sürecinde elde edilen tematik ve geometrik bilgiler, taranan obje hakkında karar vermeyi sağlamakta ve bu süreçte yardımcı olmaktadır (Reshetyuk, 2006).

Yersel lazer tarayıcıların en önemli avantajları arasında çevredeki obje geometrisini hızlı ve detaylı bir şekilde doğrudan, alanı olduğu gibi yakalama özelliği girilmesi ve ölçülmesi zor alanlarda ölçüm yaparak maliyet açısından giderlerde önemli derecede azalma sağlaması (Zeybek \& Şanlığlu 2015; Yakar vd., 2010), çok daha hızlı bir şekilde geniş alanlarda projenin hızlı ve hassas doğruluklarda sonuca ulaştırılması, klasik ölçme tekniklerinin yetersiz kaldığı, karışık, ulaşılması zor ve tehlike içeren bölgelerde ölçüm yapabilme özellikleridir. Tarama yapma işlemi sırasında çevre aydınlatmasına gerek olmadığı için günün herhangi bir zamanında tarama yaparak detayları tek ölçümde elde etme ve verilerin çeşitli amaçlarda kullanılması büyük avantaj sağlamaktadır (Reshetyuk, 2006). Bir proje gerçekleştirirken yersel lazer tarayıcı kullanımı proje sürecini ve projelerin kalitesini önemli ölçüde etkiler. Yersel lazer tarayıcı çalışma yaparken gerçek modele olabilecek en yakın modeli oluşturmak, tarama işlemi sonunda ortaya çıkacak hataları minimum düzeye indirmek, doğruluğu artırmak ve kaliteli bir model oluşturmak için diğer ölçme teknikleriyle birlikte kullanılabilir. Yersel lazer taramada elde edilen veriler yüksek hassasiyet içeren birçok işte kullanılmaktadır. Kullanılan her ölçme tekniğinde olduğu gibi lazer tarama sonuçlarında da hata oluşabilmektedir. Hataların tespiti elde edilen kalite için oldukça önemlidir. Kaliteyi etkileyen çeşitli faktörler bulunmaktadır.(Gümüş vd. 2009).

Yapılan çalışmada yersel lazer tarayıcının kullanımı hususunda dikkat edilmesi gereken noktalara dikkat çekilmiştir. Birçok alanda olduğu gibi uygulamanın avantajları ve dezavantajları vardır. 


\section{2. ÇALIŞMA ALANI}

Çalışma alanı Mersin Üniversitesi yerleşkesi içerisinde bulunan kompleks bir yapıda gerçekleştirilmiştir.
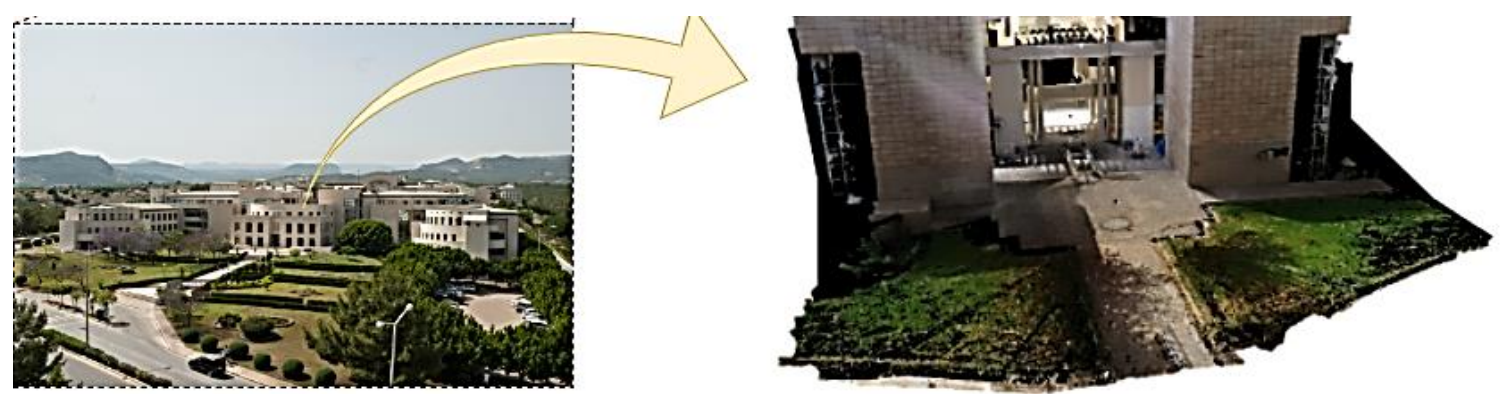

Şekil 1. Çalışma alanı

\section{MATERYAL ve YÖNTEM}

Uygulamada LiDAR yöntemlerinden olan yersel lazer tarama tekniği kullanılmıștır. Uygulamada kullanılan lazer tarayıcı FARO Focus 350S modeli bir tarayıcıdır. Kullanılan lazer tarayıcının özellikleri tablo 1 'de verilmiştir.

Tablo 1. Faro FocusS 350 özellikleri (Çelik vd. 2020; Oruç \& Öztürk 2021)

\begin{tabular}{ll} 
Tarama Mesafesi & $0.6 \mathrm{~m}-350 \mathrm{~m}$ \\
& $1 / 1,1 / 2,1 / 4,1 / 5$, \\
Çözünürlük & $1 / 8,1 / 10,1 / 16,1 / 20$, \\
& $1 / 32$ \\
Kalite & $2 \mathrm{x}, 3 \mathrm{x}, 4 \mathrm{x}, 6 \mathrm{x}$ \\
Ölçüm Hızı & 976.000 nokta/saniye \\
İç düzlük & $\pm 1 \mathrm{~mm}$ \\
Ağırlık & $4,2 \mathrm{~kg}$ \\
Boy & $230 \times 183 \times 103 \mathrm{~mm}$ \\
\hline
\end{tabular}

Lazer tarayıcıların ölçme prensibi ölçülecek nesnelere, alanlara direkt olarak temas etmeden yüksek duyarlılıkla otomatik bir şekilde bütün detaylarını detay noktalarını kapsayan koordinatlarının mesafe ölçümü ile hesaplanması çalıșmasıdır. Yapılan çalışmada FARO Focus 350S aleti kullanılmıştır. Kullanılan bu yersel lazer tarama aletinin çalışma prensibi faz karşılaştırma yöntemidir. Faz karşılaştırma yönteminde, tarama cihazı ile taranacak nesne arasındaki mesafe, yaylan ve yansıyan dalgalar arasındaki faz farkından hesaplanmaktadır (Sabuncu \& Özener 2020).

$\mathrm{Bu}$ yöntemde, aletten çıkan ve nesneden yansıyan ışının sinüs dalgasına göre karşılaştırması yapılır ve faz farkı hesaplanarak belirlenmiş olur (Vosselman \& Maas, 2010; Karasaka 2012; Beg 2018). Böylelikle lazer tarayıcı ile taranacak nesne arasındaki mesafe, gönderilen sinyal ile alınan sinyal arasındaki faz farkının hesaplanması sonucunda bulunmaktadır (Çelik vd. 2020).

$$
\Delta t=t y-t a
$$

$$
\begin{aligned}
\rho \text { sinyal } & =\mathrm{c} * \frac{\mathrm{ty}-\mathrm{ta}}{2} \\
\Delta \mathrm{t} & =\frac{\Delta \phi}{2 \pi} \frac{\lambda}{\mathrm{c}} \\
\mathrm{Rfaz} & =\frac{\Delta \varphi}{4 \pi} * \lambda
\end{aligned}
$$

Yukarıda ki eşitliklerde faz farkı ölçüm formülleri verilmiştir (Eşitlik 1, 2, 3). Zaman farkı $(\Delta \mathrm{t})$ (Eşitlik 7), gönderilen ve alınan sinyaller arasındaki farz farkı $(\Delta \phi)$ ve sinyal periyodu arasındaki faz farkı olan $\lambda / \mathrm{c}$ ile formülize edilmektedir. (Karasaka \& Beg 2021; Çelik vd. 2020 ). Faz mesafesinin hesaplanması ise eșitlik 4 ile elde edilmektedir.

YLT tekniğinin uygulamalarda birçok yönden kolaylık sağladığı bilinmektedir. Ama bu tekniğin avantajları çok olsa da dezavantajı bulunmaktadır. Teknolojinin gelişmesi ile birlikte dezavantajları daha aza indirilebilir ve daha iyi çalışma koşullarında veri elde edimi sağlanabilir.
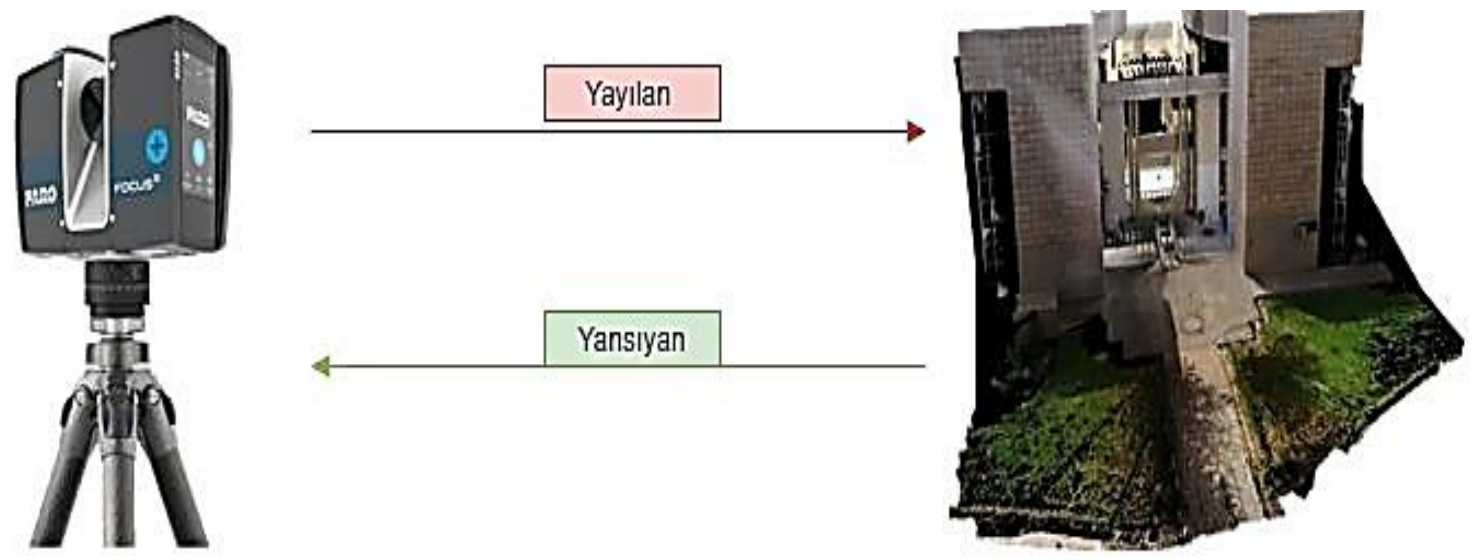

Şekil 2. Faz karşılaştırma yöntemi gösterimi 


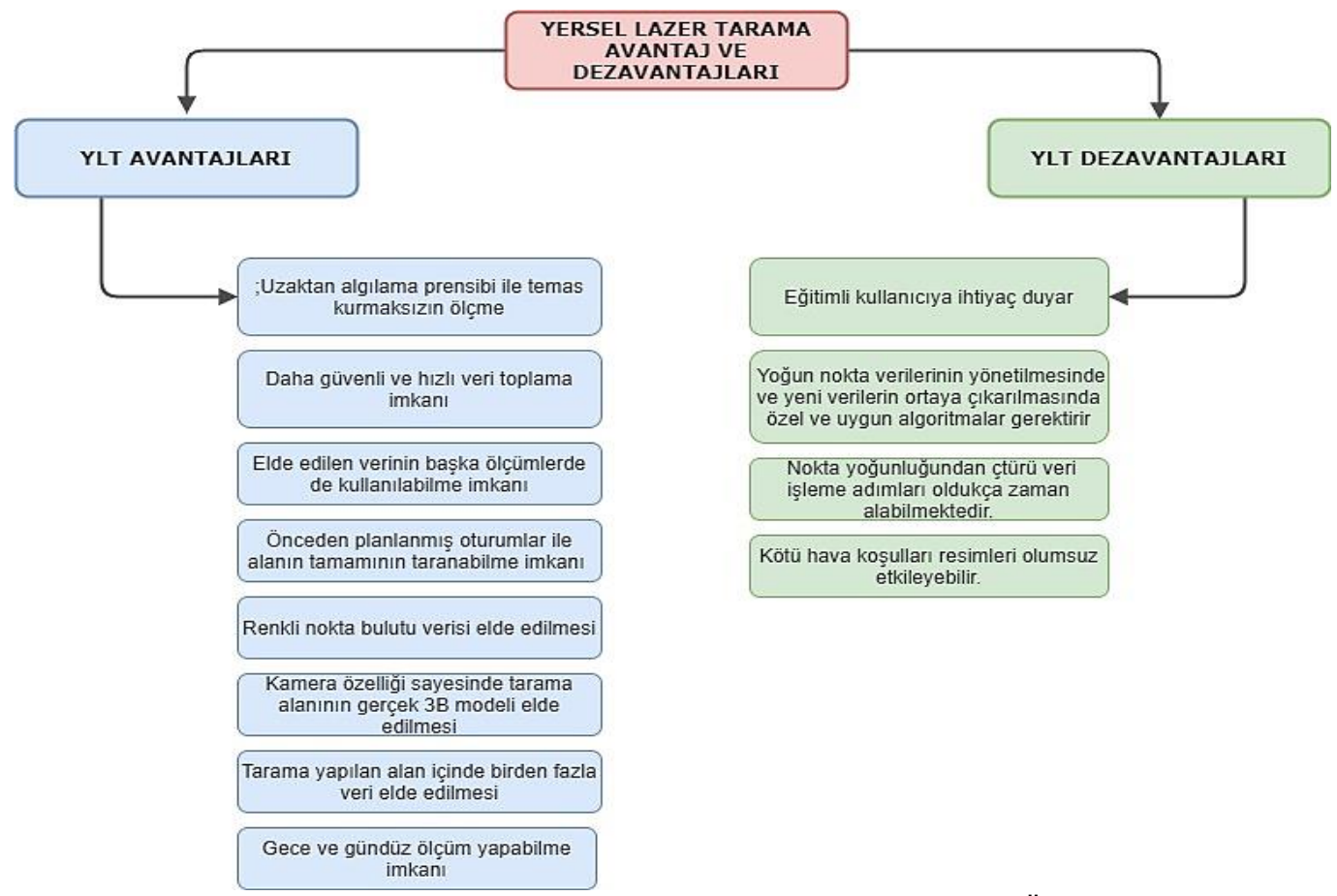

Şekil 3. YLT tekniği avantaj ve dezavantajları (Sabuncu \& Özener 2020)

\section{UYGULAMA}

\subsection{Arazi çalışması}

Arazi çalışması için önce bu araştırmanın amacına uygun bir alan seçilmesi çok önemlidir. Bu çalışmada farklı cisimlerin olması, ölçüm alanının farlı geometrik yapısının ve benzer yüzey, renk ve özelliklerinin olmasına dikkat edilmiștir.

Tarama işlemlerine başlamadan önce belirlenen araziye referans noktaları tesisi işlemi uygulanmıştır. Daha sonra total-station ile uygulama alanına tesis edilen referans noktalarının okuması yapılmıştır. Tarama işlemi yapılırken günün sabah saatlerinde tarama işlemine başlanıp öğle saatlerinde de ölçüm gerçekleştirilmesi amaçlanmıştır. Bu sayede cihazın farklı sıcaklık ve basınçlarda nasıl performans göstereceği belirlenmek istenmiştir. Öncelik olarak tarama yapılacak güne ait meteorolojiden basınç ve sıcaklık değerleri alınmıştır.

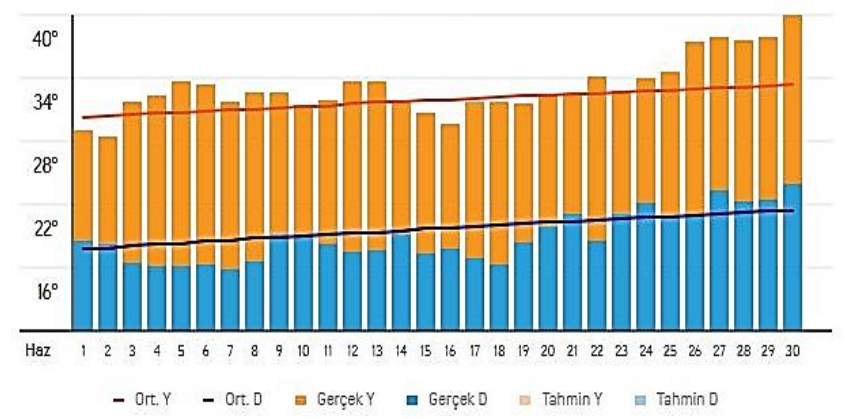

Şekil 4. Uygulama tarihi ortalama sıcaklık grafiği (URL1)
Tablo 2. 15.06.2021 hava durumu değerleri (URL 2) 15 Haziran 2021

\begin{tabular}{cc}
\hline & Gündüz $28^{\circ}$ \\
Sicaklık & Gece $24^{0}$ \\
& Hissedilen $27^{0}$ \\
Basınç & $981 \mathrm{hPa}$ \\
Rüzgâr & $6.5 \mathrm{~km} / \mathrm{s}$ \\
\hline
\end{tabular}

Tüm planlama ve hazırlık işlemleri tamamlandıktan sonra lazer tarayıcı taraması yapılan alanın tamamını tarayacak şekilde oturumlar ile ölçümlere başlanmıştır. Toplamda 6 oturum yapılarak istenilen alanın tamamının taraması yapıldı. Her bir oturum süresi yaklaşık $30 \mathrm{dk}$, çözünürlük değeri $1 / 2$, kalite değeri ise $4 \mathrm{x}$ olarak ayarlanmıştır. Sürenin ayarlanması cihazın tarama sırasında ki kalite ve çözünürlük performansından kaynaklanmaktadır. Kalite ve çözünürlük azaldıkça her bir tarama süresi de düşmektedir. Yapılan önceki ölçümlerde düşük kalite ve çözünürlük değerlerinde istenilen kalitede sonuçlar elde edilememiştir. Bu uygulamada kullanılan değerler optimum değerler olarak seçilmiştir. Cihazın bizlere sağladığı diğer yüksek çözünürlük ve kalite seçenekleri ile yaklaşı olarak 1 saatlik ve 2 saatlik oturumlarda daha net ve kaliteli sonuçlar elde edileceği görülmüştür. Ama bu oturum sürelerinin uzun olması ve hava sıcaklığının da etkisiyle cihazın ısınarak ölçüm işleminin yarıda kaldığı ve cihazın çalışma sıcaklığına geri dönmesinin beklendiği durumlar gözlenmiş̦tir. Hava sıcaklıklarının normal olduğu zamanlarda etkili bir performans sergilese de yaz aylarında hava sıcaklıklarının fazla olması, cihazın çalışma esnasında ki ısınma durumunu tetiklemektedir. $\mathrm{Bu}$ da araştırmacıya ısınan cihazın tekrar tarama yapabilir hale gelmesi süresinde bir zaman kaybı oluşturmaktadır.

Seçilen tarama kalitesi ve çözünürlük değerleri ile ölçüm işlemleri sorunsuz olarak gerçekleştirildi. Ve veriler işlenmesi için bilgisayar ortamına aktarılmıștır. 


\subsection{Verilerin işlenmesi}

Tarama verileri arazi ortamından elde edildikten sonra uygun bir yazılım olan FARO scene yazılımda işlenmesi için bilgisayar ortamına ve ilgili yazılıma aktarılmıştır. Illk işlem olarak tarama verisi yazılıma tanıtılmış ve tarama verileri uygun metotlar ile birleștirilmiștir.

Faro Scene yazilımı, bütün Faro Focus ve bununla birlikte diğer 3B tarama gerçekleştirebilen lazer tarayıcılar için geliştirilmiştir. Faro scene yazılımının özelliklerinden gerçek zamanlı tarama, nesneleri

otomatik olarak tanıma, taramaların kaydını oluşturma gibi özellikleri sayesinde tarama sonucunda elde edilen veriler etkin ve basit bir şekilde işlenebilmektedir (Karasaka \& Beg 2021).

Arazi çalışmaları sonucunda elde edilen tarama verileri yazılıma aktarılarak veri işleme (process) aşamasına geçilmiştir. Taramalar, nokta bulutundan nokta bulutuna (cloud to cloud) tekniği kullanılarak birleștirilmiştir. Nokta bulutu verisi ilgili alanın dışında, istenilen bölgenin haricinde de birçok dağınık ve gereksiz veri yani gürültü kirlilikleri içermektedir. $\mathrm{Bu}$ gürültü kirliliğine sebep olan veriler temizlenmiștir. Alana ait daha sağlıkll, doğru, hassas ve kaliteli 3B model oluşturabilmek için yapılan bu işleme gürültü giderme işlemi denilmektedir (Uzar vd. 2019, Çelik vd. 2020 ). Elde edilen nokta bulutu üzerinden katı bir model olușturulmuştur. İstenirse noktaların TLS yöntemi ile koordine edilmesi ve 3 boyutlu modeller üretilerek kesin veriler elde edilebilir (Kaya et al. 2021).

\section{BULGULAR}

Tarama ve verilerin işlenmesi aşamaları tamamlandıktan sonra renkli nokta bulutu ve katı model oluşturulmuştur.

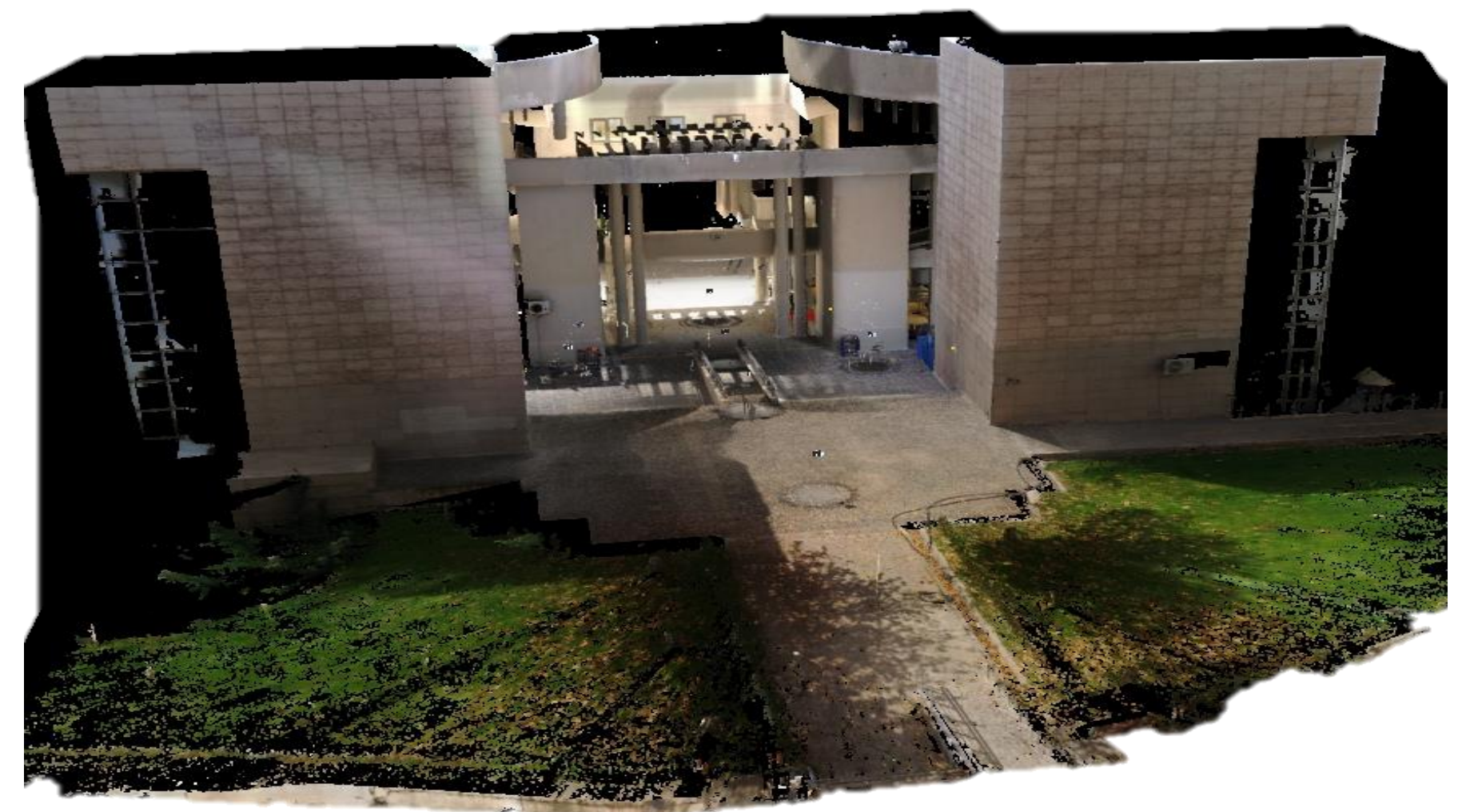

Şekil 6. Oluşturulan nokta bulutu 


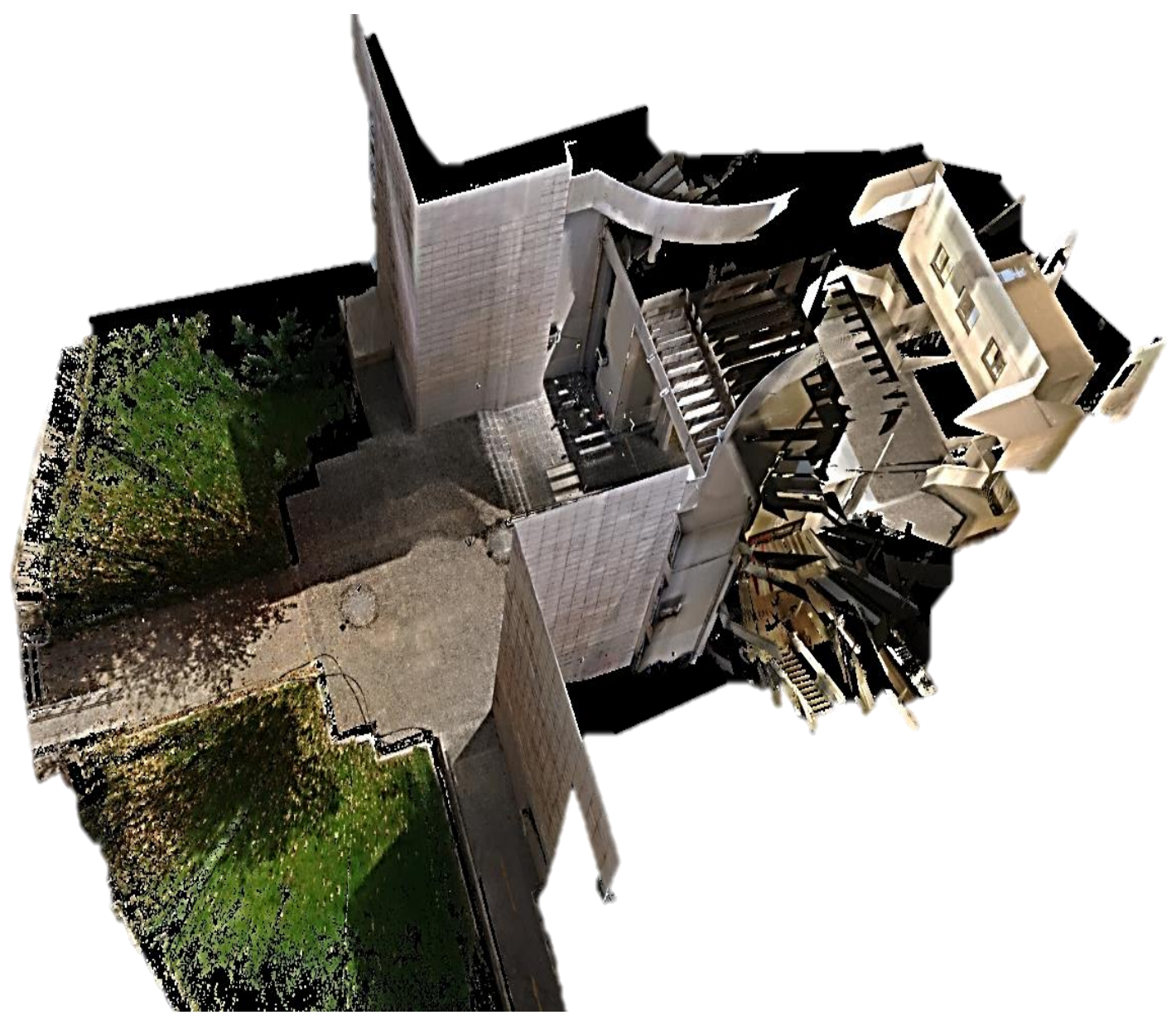

Şekil 7. Oluşturulan katı model

Yapılan taramalar esnasinda lazer tarama metodunun eksi ve artıları değerlendirilmiştir. Tarama süresi boyunca lazer tarayıcının kapsadığı alanın içerisinden geçen insanların oluşturduğu gürültü kirlilikleri veri işleme aşamasında kaliteli bir sonucun elde edilmesini engellemiştir. Bu gürültü kirliliklerinin temizlenmesi uzun uğraşlar gerektirmektedir.

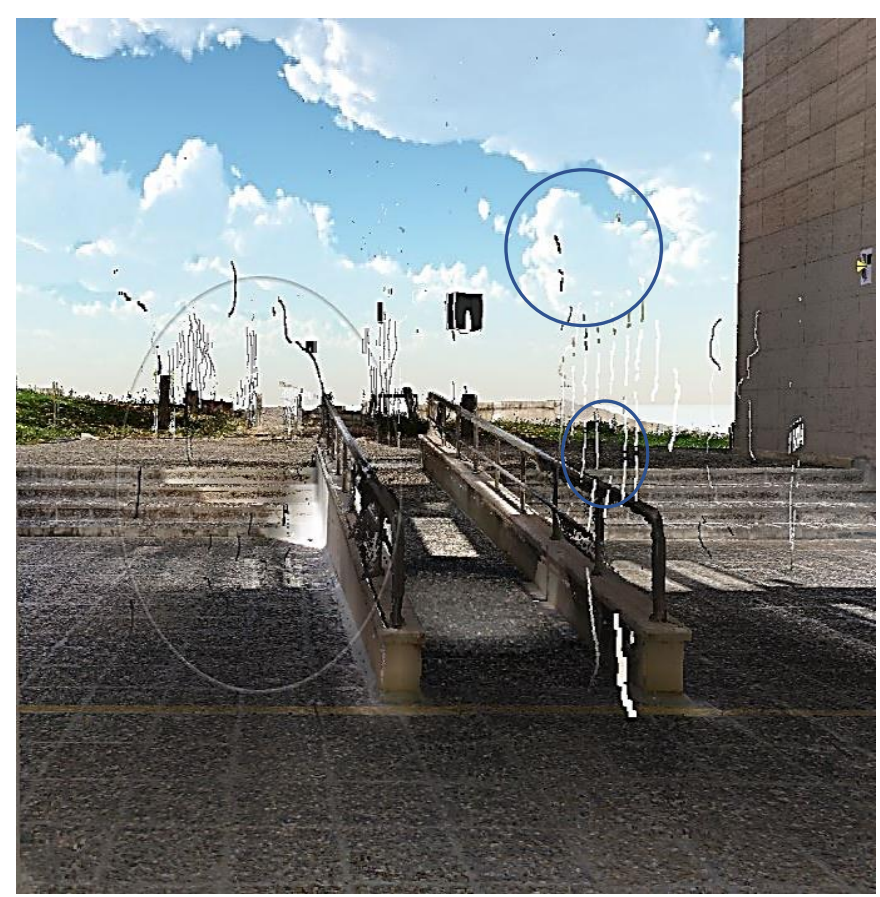

Şekil 8. Veri ișleme așamasında nokta bulutunda ortaya çıkan gürültü kirlilikleri

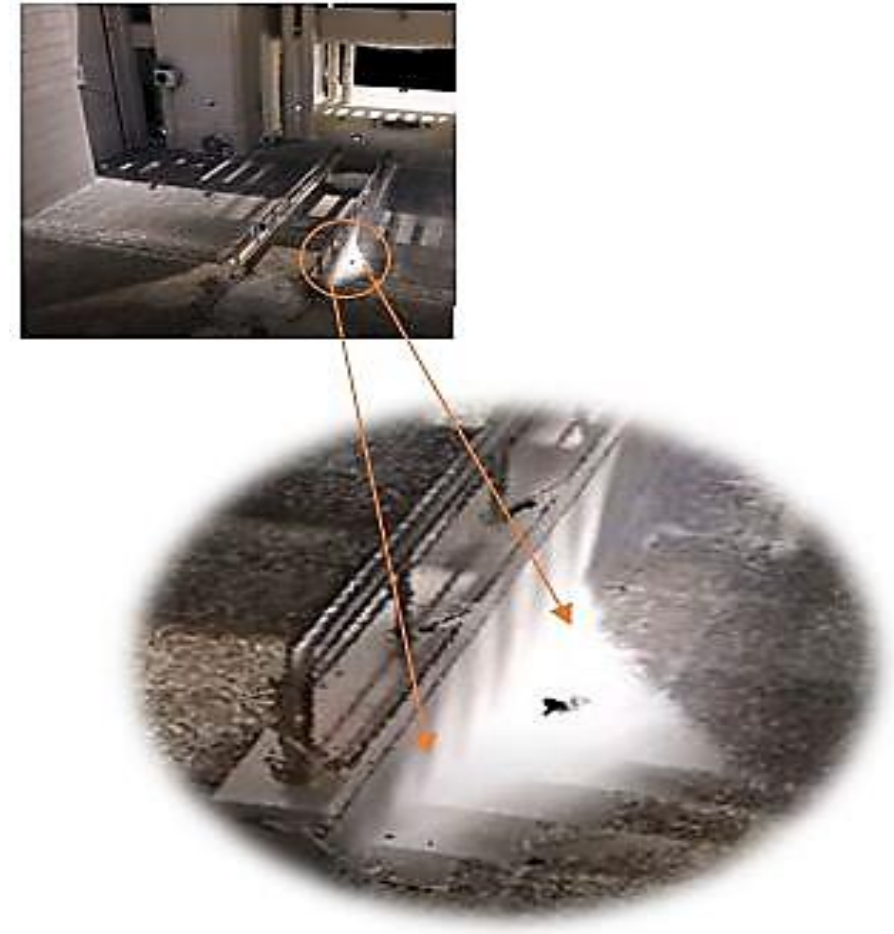

Şekil 9. Güneş ışınlarının yansımasının nokta bulutuna etkisi

Yukarıdaki şekilde güneşin yoğunlaştığı bir noktaya atılan lazer sinyallerinin geri yansıma değerlerinin az olması sinyalin saçılarak bölgeye ait verinin detaylarının çıkmamasına sebep olmuştur. Güneş ışınları o noktada parlama yaparak alanın parlamasına sebep olmuştur. Beyaz yüzeylerde yansıma çok fazla meydana gelirken 
siyah yüzeylerde daha az olmaktadır. Renk çeşitliliği fazla olan yüzeylerde yansımaya etki olarak lazer aletinin spektral özellikleri de önem arz etmekte ve buna göre değişiklik göstermektedir (Boehler vd. 2002). Bu da veri işleme noktasında lazer cihazında bulunan yüksek çözünürlüklü kameranın resim çekme aşamasında güneş ışınlarının nüfuz ettiği alanın yansıma yaparak ilgili yüzeyin detay noktalarının ortaya çıkmasını engellediği görülmüştür.

Bu gibi durumlarda cihazın bizlere sağladığı güneşin havada konumlanmasına göre seçim şansı verdiği üç seçenek mevcuttur. Bu seçenekler güneşin ufuk çizgisi, başucu ve eşit ağırlıklı olmak üzere güneşin geliş noktasına göre seçim yapmamıza imkân vermektedir. Başucunda güneş en tepedeyken, güneșin yeni doğması ve batmaya başlaması aşamalarında ufuk çizgisi düzlemi, güneş tam tepe noktasında ise başucu seçeneği seçilerek aletin güneş ışınlarına göre kendini ayarlaması ve kaliteli veri elde edilmesi yönünde ayarlanması sağlanır. Burada meydana gelen durum bu seçimlerin uygun seçimin yapılmamasından kaynaklanabileceği ön görülmüştür.

Veriler işlendikten sonra ortaya çıkan sorunlardan biri de çalışma alanında bulunan bazı objelerin sinyal yansıtımının saçlarak alete gelmesi gereken verinin tam anlamıyla gelmeyerek saçılmasından meydana gelmektedir. Bu saçlmalar nokta bulutu verisinde gürültü kirlilikleri de oluşturabilmektedir. Genellikle bu objeler cam yüzeyler (șekil 10) , alüminyum gibi parlak metal yüzeyler (şekil 11) olarak görülmüștür.

Bu noktadaki hatalar, taranan objeler ile alakalıdır. Bu hataların en önemli kaynağı, ışının çarptığı objenin geri yansıtım oranlarındaki değişikliklerden meydana gelmektedir. Yersel lazer taramada bu gibi durumların ortaya çıkması yansıma durumuna bağlı olduğu belirtilebilir (Reshetyuk, 2006). Yansıtım değerleri, gönderilen sinyal ile lazer cihazına gelen sinyalin gücü arasındaki oran olarak tanımlanabilir. Objenin materyal özellikleri, elektrik aktarması ve iletkenliği, objenin dıș kısmının rengi, lazerin dalga boyu lazer ıșınının geldiği açı, yüzeyin yapısı ve nemi gibi faktörler önem arz etmektedir (Lichti \& Harvey, 2002; Ingensand, 2006; Reshetyuk, 2006; Staiger, 2005) Nokta bulutunda bu cisimlerin şekillerinin bozuk veya bazı açlarda hiç veri alınamadığı görülmüştür.

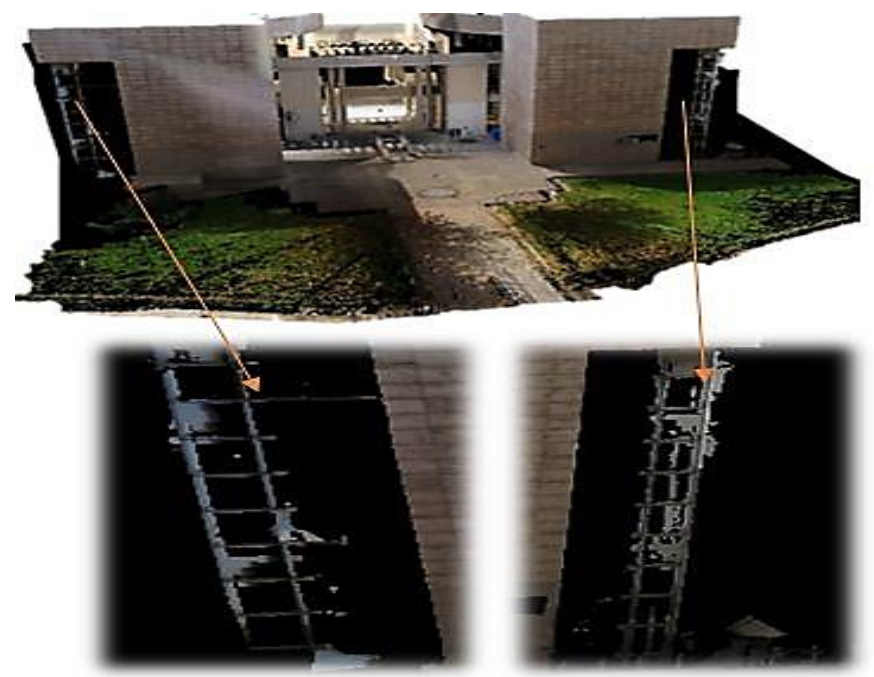

Şekil 10. Cam yüzeylerde bozulmalar

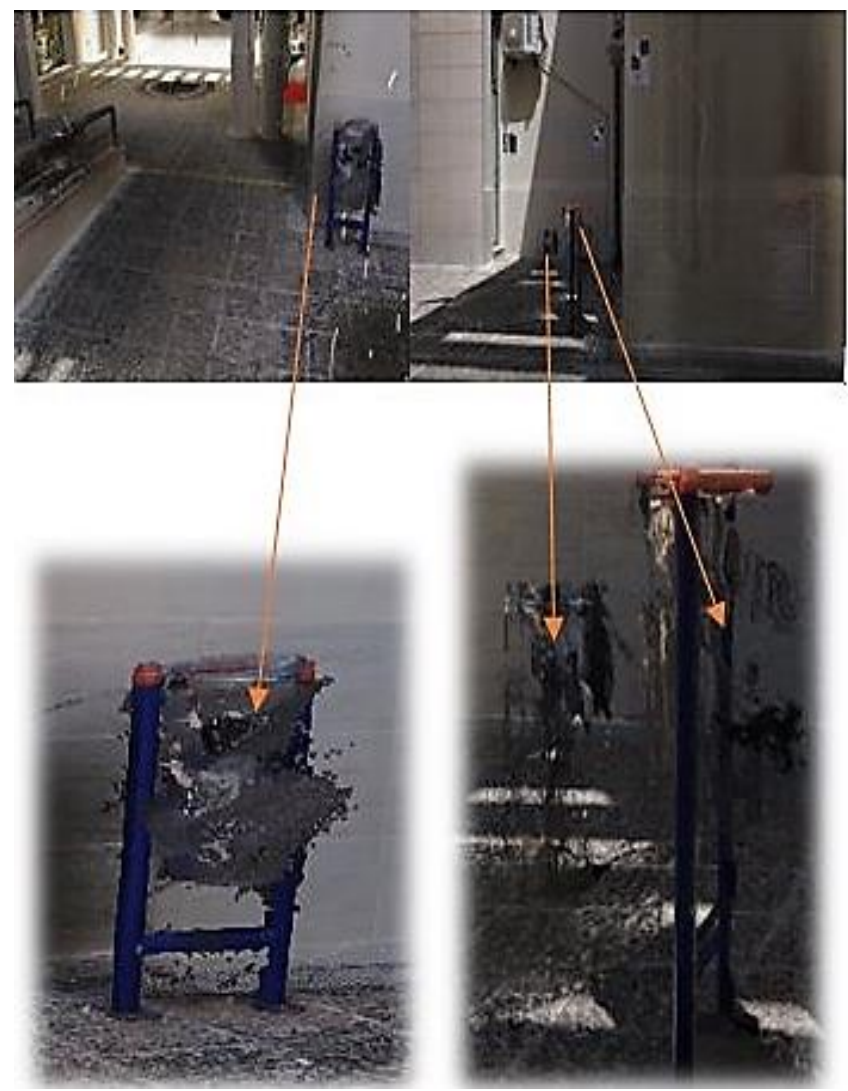

Şekil 11. Metalik, parlak yüzeylerde bozulmalar

\section{SONUÇLAR}

İlerleyen teknoloji her alanda olduğu gibi ölçme sistemleri ve aletlerinde büyük gelişim sağlamıştır. Bununla birlikte son zamanlarda yersel tarama teknolojisinin kullanımı oldukça artmıştır. Olabilecek en az maliyetle ve zamanla hızl, kaliteli 3B boyutlu bilgiye ulaşmak önem arz etmektedir. Yersel lazer tarama da bize bu imkânı sağlamaktadır. Günümüzde birçok sektörde sağladığı imkânlar nedeniyle yersel lazer tarama kullanılmaktadır.

$\mathrm{Bu}$ çalışmada yersel tarama teknolojisi kullanılırken nelere dikkat edilmeli ve bu teknolojinin avantajı ve dezavantajı görülmeye çalışılmıştır. Çalışma alanı olarak Mersin Üniversitesi yerleşkesinden bir bölge seçilmiştir. Kullanılan lazer tarayıcı FARO Focus 350S, yazılım ise Faro Scene yazılımıdır.

Tarama sonucunda yüksek kalitede ve çözünürlükte veriler elde edilmiştir. Ölçüm yapılırken cihazın hava sıcaklığından etkilendiği gözlenmiştir. Bu da zaman kaybına neden olmuştur. Tarama esnasında oluşan gürültü verileri esas istenen verinin kalitesini etkilemiştir. Güneşin fazla olduğu noktalarda oluşan parlaklı nedeniyle detayların fazla çıkmadığı görülmüștür. Tarama ortamında bulunan cam vb. objelerin ise lazer ışınının saçılmasına neden olduğu belirlenmiştir.

Yapılan çalışmalarda bu gibi eksiklikler çıksa da yapılan araştırmalar sonucunda ortaya çıkan deformasyonların giderilmesine olanak sağlayan yazılım ve programlar olsa da daha da gelişerek iyi sonuçlar veren yazılımların ortaya çıkması gelişen teknoloji ile birlikte beklenen bir durum olarak görülmektedir. 


\section{Yazarların Katkısı}

Yazarlar bu araştırma makalesine eşit katkı sunmuşlardır.

\section{Çıkar Çatışması Beyanı}

Yazarlar arasında herhangi bir çıkar çatışması bulunmamaktadır.

\section{Araştırma ve Yayın Etiği Beyanı}

Yapılan çalışmada araştırma ve yayın etiğine uyulmuştur.

\section{KAYNAKÇA}

Alptekin A, Çelik M Ö, Doğan Y \& Yakar M (2019). Mapping of a rockfall site with an unmanned aerial vehicle. Mersin Photogrammetry Journal, 1(1), 1216.

Beg A A (2018). 3 Boyutlu Modellemede Yersel Lazer Tarama ve İnsansız Hava Araçları Verilerinin Entegrasyonu ve Kilistra Antik Kenti Örneği. Yüksek Lisans Tezi, T.C. Selçuk Üniversitesi, Fen Bilimleri Enstitüsü, Konya.

Boehler W, Vicent M B \& Marbs A (2003). Investigating laser scanner accuracy. The International Archives of Photogrammetry, Remote Sensing and Spatial Information Sciences, 34(5), 696-701.

Çelik M Ö, Hamal S N G \& Yakar İ (2020). Yersel Lazer Tarama (YLT) Yönteminin Kültürel Mirasın Dokümantasyonunda Kullanımı: Alman Çeşmesi Örneği. Turkey Lidar Journal, 2(1), 15-22.

Erener A \& Yakar M (2012). Monitoring Coastline Change Using Remote Sensing and GIS Technologies. Lecture Notes in Information Technology, 30, 310314.

Gümüş K, Erkaya H \& Tunalığlu N (2009). Yersel Lazer Tarama Verilerinde Çevresel Ve Objesel Nedenlerden Kaynaklanan Hatalar. Türkiye Harita Bilimsel ve Teknik Kurultayı, Ankara, 137-138.

Hamal S N G, Sarı B \& Ulvi A (2020). Using of Hybrid Data Acquisition Techniques for Cultural Heritage a Case Study of Pompeiopolis. Türkiye İnsansız Hava Araçları Dergisi, 2(2), 55-60.

Ingensand $\mathrm{H}$ (2006). Methodological aspects in terrestrial laserscanning technology, 3rd IAG Symposium of Geodesy for Geotechnical and Structural Engineering and 12th FIG Symposium on Deformation Measurements.

Karasaka L \& Beg A (2021). Yersel Lazer Tarama Yöntemi ile Farklı Geometrik Yapıdaki Özelliklerin Modellenmesi. Geomatik, 6(1), 54-60. DOI: 10.29128/geomatik.664728
Karasaka L (2012). Mobil Yersel Lazer Tarama Sistemlerinin Fotogrametrik Rölöve Projelerinde Kullanılabilirliği Üzerine Bir Çalışma. Doktora Tezi. Konya, Selçuk Üniversitesi, Fen Bilimleri Enstitüsü.

Oruç M E \& Öztürk İ L (2021). Usability of Terrestrial Laser Technique in Forest Management Planning. Turkey Lidar Journal, 3(1), 17-24.

Reshetyuk Y (2006). Calibration of terrestrial laser scanners for the purposes of geodetic engineering, 3rd IAG Symposium of Geodesy for Geotechnical and Structural Engineering and 12th FIG Symposium on Deformation Measurements.

Sabuncu A \& Özener H (2020). Mimari Dökümantasyonda Yersel Lazer Tarama Teknolojisi Kullanımı: Tarihi Sismoloji Binası Örneği. Turkish Journal of Remote Sensing and GIS, 1(1), 45-52.

Staiger R (2005). The Geometrical Quality of Laser Scanner (TLS). In Proceedings of FIG Working Week, 1-11 and GSDI-8, 16-21 Nisan, Kahire, Misır.

Ulvi A \& Yakar M (2014). Yersel Lazer Tarama Tekniği Kullanarak Kizkalesi'nin Nokta Bulutunun Elde Edilmesi ve Lazer Tarama Noktalarının Hassasiyet Araștırması. Harita Teknolojileri Elektronik Dergisi, 6(1), 25-36. Retrieved from https://dergipark.org.tr/tr/pub/hartek/issue/758 9/99627

Ulvi A (2021). Documentation, Three-Dimensional (3D) Modelling and visualization of cultural heritage by using Unmanned Aerial Vehicle (UAV) photogrammetry and terrestrial laser scanners. International Journal of Remote Sensing, 42(6), 1994-2021.

Uzar M, Tunalığlu N, Arıcan D \& Arda T (2019). Yersel lazer tarama verisi ile elde edilen $3 \mathrm{~B}$ modellerde filtreleme etkisinin araştırılması. Gazi Üniversitesi Mühendislik Mimarlık Fakültesi Dergisi, 34(4), 1765-1776. DOI: 10.17341/gazimmfd.571546.

Vosselman G \& Maas H (2010). Airborne and Terrestrial Laser Scanning. CRC.

Yakar M, Yıldız F \& Yılmaz H M (2005). Tarihi Ve Kültürel Miraslarin Belgelenmesinde Jeodezi Fotogrametri Mühendislerinin Rolü. TMMOB Harita ve Kadastro Mühendisleri Odası, 10.

Yakar M, Yılmaz H M \& Mutluoğlu H M (2009). Hacim Hesaplamalarında Laser Tarama ve Yersel Fotogrametrinin Kullanılması, TMMOB Harita ve Kadastro Mühendisleri Odası 12. Türkiye Harita Bilimsel ve Teknik Kurultayı, Ankara.

Yakar M, Yilmaz H M \& Mutluoglu O (2010). Comparative Evaluation of Excavation Volume by TLS and Total Topographic Station Based Methods. Lasers in Engineering 19(5-6), 331-345. 
Yılmaz H M \& Yakar M (2008). Computing of Volume of Excavation Areas by Digital Close Range Photogrammetry. Arabian Journal for Science and Engineering 33 (1A), 63-79.

Yılmaz H M, Mutluoğlu Ö, Ulvi A, Yaman A \& Bilgilioğlu S S (2018). İnsansız Hava Aracı ile Ortofoto Üretimi ve Aksaray Kampüsü Örneği. Geomatik Dergisi. 3(2), 129-136.

Yilmaz H M, Yakar M, Mutluoglu 0, Kavurmaci M M \& Yurt $\mathrm{K}$ (2012). Monitoring of soil erosion in Cappadocia region (Selime-Aksaray-Turkey). Environmental Earth Sciences, 66(1), 75-81.

Zeybek M \& Şanlığlu İ (2015). Accurate determination of the Taşkent (Konya, Turkey) landslide using a long-range terrestrial laser scanner. Bulletin of Engineering Geology and the Environment, 74(1), 61-76.
URL1:https://www.accuweather.com/tr/tr/mersin/31 7935/june-weather/317935

URL2:https://yandex.com.tr/hava/mersin/month/june

This work is distributed under https://creativecommons.org/licenses/by-sa/4.0/ 